\title{
Sense variability and typology of cultures
}

\author{
Vadim G. Lankin ${ }^{1, a}$, Anastasiia O. Shatokhina ${ }^{1}$ \\ ${ }^{1}$ Tomsk Polytechnic University, 634050 Lenin ave., 30, Tomsk, Russia
}

\begin{abstract}
The article is concerned with the problem of justification of cultural (civilizational) typological diversity, which is being analyzed in the framework of variant types and meaning-making methods. Authors attempt to prove the leading role of these methods in shaping cultures' idiosyncrasies, as well as a specific course of their evolution, and sustainability as culture-transforming programs. In the article, the criteria of distinguishing historical culture types set in the XIX-XX centuries by the most influential civilizational concepts are analyzed, and a new criterion is proposed. This is the criterion of the meaning-making method which is considered the most applicable to describe the core of any culture as an integrity of both experimental and textual ways of human existence re-examination. A number of culture (civilization) types were used as examples; the article observes how the key meaning-making model sculpts the civilization as a unique entity and defines it.
\end{abstract}

\section{Introduction}

The civilization approach in history, in theory and philosophy of culture allowed us to point out quite a few comparative aspects allowing detailed comparison and generalized juxtaposition of their idiosyncrasies. Today, in the context of growing cultural interaction, which means not only competition of civilizations and their interinfluence, but escalation of conflicts and collisions, it is important to realize what lies behind those differences that not only have brought about the vast variety of civilizations but also have ensured their qualitative diversity. To what extent are they mutually irreplaceable and, consequently, can they make possible alternative patterns for human and social development? What is it that makes them different as cultures, in the first place, not social civilizational systems? Are there any criteria of distinguishing cultures avoiding the specific conditions of their emergence, on the one hand, and, on the other hand, the idea of any culture's unsearchable psyche, mentality or fate? To put it another way, the question is not simply about reasons for comparing cultures, but is about constitutive grounds for understanding culture types. To approach the question, the system theory cannot be applied, its incompleteness considered, though a number of valuable hypotheses have been advanced to adapt it to this field of expertise. The majority of recent researches referring to the typology of cultures lie within modernization and globalization paradigms, where the aspect of perspective cultural interaction comes to the forefront [1,2]. However, there are new works that explain the diversity of culture types through relativism and essential pluralism $[3,4]$.

The term «cultural-historical type» was introduced in the 19-century, and a century later, was extended by the idea of «civilization». The word «civilization» is used to name many different phenomena, but here it is referred to as the whole of all aspects of a certain community's life, including the impacts of geographical and natural conditions. Such generalizing definition comprises both the culture type, and the socio-economic and geopolitical characteristics of the culture's development. Among the other equivalents are also «socio-cultural supersystems» (P. Sorokin), «great cultures» (N.Berdiajev), «cultures as organisms» (O. Spengler), «cultural systems» (F. Northrop), or «world cultures» (A. Toynbee). Behind each of these, there normally stands a criterion model of justification, distinguishing, and juxtaposition of culture types.

According to N.Y. Danilevsky, every culture's development is based on certain goals, or, in his words, «spiritual missions» of cultural creating, that determine the nature of the process. O. Spengler distinguished a number of main cultures describing those as completely different cultural worlds genetically rooted in «prasymbols» and «pre-phenomena». M. Weber builds up his typology of cultures by discerning various, inspired by religious ethics, types of the activity approach to the world, and advances the criterion of configuration of the values driving the ideal goal setting process. The religious aspect plays an important role in A. Toynbee's and S. Huntington's models of cultural typology, as well. $\mathrm{S}$. Huntington regards religions as supernational and

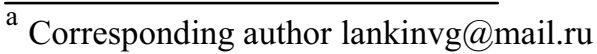


superstate communication bases, instruments of unification and integration stimulating the emergence of vast cultural communities [5]. P. Sorokin relates to socio-cultural systems, each of which is based on a particular phenomenon of consciousness. To consciousness, he ascribes the power that modifies the natural environment and defines the essence of every culture. He calls this power «superorganic». The main criterion of typological differentiation, as stated in P. Sorokin's theory, is people's concept of reality.

Culture types are mostly regarded from the viewpoint of binary oppositions like the notorious "West" and "East" concepts.

F. Northrop's typology of cultures is based on methods of cognitive activity. In terms of the eastern culture, intuitive and irrational worldview, as well as the value-based approach to work are typical, while the western culture relies on science-based knowledge [6]. The cultural concepts of «West» and «East» used to be highly generalized and all about binary oppositions like collectivism - individualism, intuitivism - rationalism, traditionalism - dynamism etc. However, the structure of cultural variety, yet to be defined by the cultural theory, is obviously more complex than that. Besides, behind each of these pairs there is a contradiction of civilization and barbarism as a fainted sound of presence-absence logic. It should be noticed, however, that the category of tradition here does not have the idea of difference: it conveys the idea of cultures' identity and continuity, but is not used as a criterion for distinguishing their differences. To explain the difference in traditions, more precise criteria are needed. The tradition as such should be viewed on as a means of conveying cultural patterns and senses, a way of maintaining identical culture types, not as a source of new types or an entity conditioning their idiosyncrasy.

\section{Materials and methods}

We suggest culture be considered as a program and experience of understanding and re-examining the natural human and societal existence, of supernatural meaning-making. Yet how could one justify and realize the sense variability, in other words, discern a potential difference in the uniformity of the category under consideration? It is possible, provided one recognizes the meaning as a constructive event, when the integrity is shaped in acts of consciousness, not simply as a matterof-fact. In fact, these acts are meaning-making discourses, in which the phenomenon of integrity is performed and defended. As for the culture, it contains, as an experience of re-examination, the foundational structure of meaning-making which is more fundamental than that of interacting between the culture and nature, or society. Furthermore, the variability of this structure is responsible for the principles of culture types' diversity.

Senses (or meanings) are a system of axes of the logical opportunities, in which the human nature in the phenomenon of culture is drawn. The system of senses is the system of the logically possible whose coordinates influence the way the experience of culture is arranged.
The senses are coordinate systems of the logical opportunities inside the phenomenon of culture the human gets involved in. The system of senses is a system of the logically possible, according to which coordinates of the culture experience is formed. Yet as the human consciousness defines life as conceivable and value-oriented, we have to deal with versions of something where a concept of dignified human life can be traced, that is a concept of a human, as a result of reframing human natural existence (as a culture concept). We come across variants of meaning-making, in which framework, or coordinate system, human activity attains its integrity. Hence, we can state the variety of cultures rests on the variety of forms of meaning-making. We have to accept that the sense is not a matter-of-fact, but an event of meaning-making process, of realization (or a discourse event, an event of meanings juxtaposition, as it is in this case). Its structure is relevant to the reflexive nature of consciousness, which is represented by the phenomenal «own»«other» correlation. In a realization event, the meaningmaking process can be focused both on the «own» and the «other», «I myself» becoming meaningful in the light of this «other» superior sense. Also, the complementarity of the «own» and the «other» can develop, in which case both are evaluated as equally powerful sides in terms of the specific, meaning-making, function of their interconnection and complementation.

Three main methods of sense realization can be pointed out: rational, aesthetic and mystic. These are found in the three intellection types: active-cognitive with the rational method dominating, imaginativemeditative with the aesthetic aspect of sensation being prevalent), and religious-ascetic and conscientiousethical based on the intuitiveness of the meaning-making «other», i.e. on the «other-dominance» («heteronomousity») of sense. The rational modus of meaning-making conveys the principle of consciousness as of self-assertiveness, the aesthetic modus the principle of self-replenishment, the mystic modus the principle self-renewal. These modi are equal in value, one should not be preferred to the detriment of the others. Yet they are not equivalent, as each of them offers different possibilities of perception (and existence). The modi complement one another, but at the same time, they are in a constant conflict and can extrude the competitors out of a human's consciousness, as well as out of the space of cultural diversity.

The approach we offer is very strict in terms of methods: it enables us to consider the culture as the experience of realization, whose foundation is a variant meaning-making structure and which, in its active existence, is a meaning-making discourse where different modi of meaning-making interconnect, compete and complement each other in relatively stable combinations. The hypothesis states, every one of the original civilizations qualified as world civilizations, roots in a peculiar cosmos of sense, which as such is a specific hierarchical interconnection between the main meaning-making modi.

We carried out a comparative study of well-known civilizations, in the aspect of their most essential 
achievements which stand out as most prominent, and were borrowed by other civilizations. We succeeded in establishing a correspondence between these achievements and culture forms of different, meaningmaking modalities. It should be noted that there were also certain forms found where every civilization lagged behind and which were compensated by relevant borrowings. The study also revealed the factors of mentality characteristic of any of the cultures under analysis, demonstrate a relatively stable structure of meaning-making discourse. The structures are revealed both in key philosophical, religious and aesthetic ideas, and in value priorities reflected in examples of conventional wisdom.

\section{Results and discussion}

The analysis has allowed establishing the correspondence of the main world civilizations' culture types, on the one hand, and, on the other hand - of the meaning-making systems which are not only based on a dominant meaning-making modus, but also on a hierarchical structure in the three modi's interrelations: the rational, the aesthetic and the mystical one. One could state that the system of culture types is a system of hierarchical logical interrelation of the main meaningmaking lines which is both idiosyncratic and stable.

1.The Western civilization has one culture type, because in spite of all the impacts and inclusions taking place during the whole period of its history, it has developed one and the same hierarchy of meaning (and value) lines: rational-aesthetic-(mystical). The rational is dominating and is taken as the sense as such. The aesthetic, while being subject to the rational, acquires the shape and sense of its own. This is the meaning-making skeleton of the West European civilization, from ancient Rome to the present-day North America that has become the political center of the Western civilization. The religious-mystical component is not considered essential, and, if not completely marginalized; it adheres to the rational phenomena of power, justice, moral, or performs the function of consolation.

2. The culture type of Ancient Greece is significantly different in terms of the subordinative structure of the meaning-making compound which looks like "aestheticrational-(mystical)'. The sphere of the highest priority through the classical period was the arts whose influence on all the next epochs could hardly be overestimated. As compared with the arts, the philosophy was not of much significance, to neither other civilizations, nor ancient Greeks themselves. For Greeks, the world was a harmonic cosmos, and this view was fundamental both for the philosophy and for the arising science. The religion was also of an aesthetic nature, putting forth mythopoetry instead of dogmatism, and mysteries instead of cult canons.

3. China and East Asia presented a very peculiar compound of value- and sense-oriented references: aesthetic-mystical-(rational). The art in the Chinese traditional culture is by no means restricted by the sphere of fine arts (as it mostly is in the European concept).
Instead, this is an all-encompassing category of culture embracing martial arts, art of war, art of health maintenance, strict rituals at all levels of the sociocultural hierarchy. The aesthetic is primary, while the mystical is secondary: instead of notions of the transcendental, there is the idea of the miraculous emerging and disappearing of everything. The rational forms, in turn, are regarded in the East traditional cultures as a dangerous hindrance on the human heart's path.

4. In South Asia (India) rationalism is intertwined with mysticism, pushing aestheticism aside. In Indian culture, the mystical contemplation is subjected to the rational lying at the heart of the superior knowledge that gives power and enables to rule both the material and spiritual aspects of the subjective world. Hinduism and its New Age variations emphasize the superiority of esoteric knowledge as opposed to faith. The most essential creation brought into life by the synthesis of the rational and the mystical is magic, which is manifested in Brahmans' competence to control gods, and in yogis' ability to control their body and spirit.

5. Christianization brought forth a new culture type in East Europe. For the Byzantine Empire and later, for Russia and other countries of the Orthodox civilization (as A. Toynbee called it), the hierarchy inside the compound of sense and values (axiological) looks as follows: mystical-aesthetic-(rational). The primary sense of a human life, as regarded in the discourse of this civilization, is in unity of man with God achieved through spiritual deeds, i.e. righteousness, prayers and penitence. The technological rationality is considered an important part of life but not a value in itself. As a rule, the constant lack of the rational factor is compensated by historically significant borrowings, primarily, from the nearby West.

A specific culture type is represented by the Near East. In spite of the impressive diversity of ethnoses and civilizations, it has a peculiar hierarchy of values and notions which has been reigning here for thousands of years: mystical-rational-(aesthetic). Hinduism and Islam belong to this class of semantic (notional) phenomena. The freedom of art is severely curtailed, some genres being prohibited by the religion. The mind is focused on scrupulous expounding of the mystical revelation, and as its extension, shapes the specific character (mix of rationality and legalism) of the mystical component, and the culture type as such.

This theory allows understanding that there exist various culture types with the same meaning-making model dominating; still, they will differ in the hierarchy of other meaning-making motives, as a result, preserving their sense uniqueness. It will depend on the proportion of the primary meaning-making modus with the secondary one, the proportion forming as a specifically constructed semantic discourse of the culture. The aesthetic meaning-making component dominates in both ancient Greece and traditional Chinese culture, but that does not keep them from being completely different from each other in their main features.

The mysticism-oriented cultures of the Orthodox and Islamic worlds are also partly alike, but the mystical 
intuition is different in these cultures. In Orthodoxy, it is reinforced by the phenomenon of the God loving and merciful, which results in the specific relationships between Him and a man, the relationships that by nature are close to sympathy and compassion. In Islam, the mysticism rests on practical rationalism that manifests in the strict moral spreading into the law and revealing the God's imperious and willed essence.

Distinguishing reason as the meaning-making basis of Indian culture may seem counterintuitive, the mystical reputation of India taken into account. But a closer look reveals an astonishing connection between religion and magic which differs from that in Taoism, for example. The major part of Vedic texts is incantations and rituals descriptions, and the Vedas deliver first of all knowledge, not worship. Referring to Vedanta's doctrine, its world outlook developed in Upanishads one will be surprised how close the key correlation of Atman and Brahman is to what we have defined as a phenomenal disposition of the rational type of consciousness. Of course, we cannot deny the meaning of art in Indian or any other culture. But we should pay our attention to the fact that the phenomenon of tragedy with its semantic commotion is not known to the Eastern cultures, it is extremely far from the traditional Indian culture.

Another example is Buddhism, the fruit of Indian culture, which spread to the East - China and Japan. Buddhism is rationally magic; it rests on the intuition of reason rather than mysticism. The culture type of China and the whole East Asia is different: it is the feeling of wonderful Dao - invisible and inexplicable source of all the emergences, merged with mysticism, but filling it with its own meditative-aesthetic contemplation. Thus, Zen-Buddhism (the Buddhism of East Asia) is a significant transformation of the Indian prototype.

But is the birth of identical semantic types on different historic grounds possible? An answer can be given by a closer look at one of the youngest civilizations known, i.e. Latin America. Some scientists, including S. Huntington, identify it as a separate civilization.

First and foremost, it is its cultural-typological difference, which is so crucial that a communication gap between representatives of this culture and others is quite noticeable. We can state that Latin American civilization exists not merely as a geopolitical area, but as a culture type taking its own place among other civilizations, provided it reproduces the described structuralhierarchical model. Explicit cultural identity, reflected in O. Paz's characteristic of the semantic world of Latin American civilization [7] takes place. We should admit a significant inversion of meaning-making variables that occurred in Europe orientated culture of Latin America. The analysis of meaning-making motives of the culture leads to the following structural-hierarchical model: aesthetics - reason - mysticism. This confirms that logical possibility of the culture type, the possibility of the phenomenal-semantic structure, lying at the root of culture types, exists and can materialize regardless of the direct historic translation impact. This also confirms that emergence of similar semantic models of culture in history does not lead to appearance of absolutely identical cultures. Typologically similar cultures are also not identical in the forms of communication between their structural-semantic aspects.

\section{Conclusion}

The given structural-phenomenological theory of culture as «semantic cosmos» allows us to draw the following conclusions:

1. The existence of culture types means the existence of semantic types of intellection and activity which are relatively stable. The meaning-making structure resembles a system of coordinates with a strict hierarchy of meaning-making modi, which is supported by the semantic system of language and communication stereotypes, and agrees with characteristic models of social relations.

2. The theory particularizes the principal approach to culture types as to those of equal value but not really equivalent, they are regarded as logically supplementing each other, while their competition in history is not taken into consideration as a matter of priority.

3. The theory described can be called a theory of «semantic worlds», but it does not isolate these worlds. Moreover, it allows finding out the logic of cultural exchange which is as follows: every culture tends to compensate the aspects of realization and creation that are not considered foremost within its dominant discourse, but that nevertheless are vital for a stable and competitive development of the civilization. It is done by means of borrowing achievements from cultures which prioritize these exact aspects and succeed in their realization. These "export" and "import" of cultural values has a long history. In the context of global integration these processes are developing.

The theory allows us to concretize the logic of communication and interaction between civilizations. In contrast to the extreme concept of non-interpenetrating cultural worlds we reveal the configuration of culture types' complementarity. The willingness to compensate lack of achievements in the fields, taking peripheral position within the meaning-making structure encourages the cultures to communicate and borrow from one another. At the same time, they are ready to transmit not only their own outstanding achievements but corresponding meaning-making samples. Permanent inner discourse allows and even encourages involving typologically alien senses as familiar ones in the field of culture and finding place in the own semantic order for the borrowed samples.

In addition, the theory allows us to avoid the other logical extreme which states that cultures are capable of producing new synthetic entities all the time. The synthesis is carried out by every culture type on the basis of their meaning-making matrix.

\section{Acknowledgment}


The authors are grateful to the organizers of the International Conference on Research Paradigms Transformation in Social Sciences for the opportunity to exchange creative ideas, and to Tomsk Polytechnic University for the assistance in publishing results of research in the high ranked journals.

\section{References}

1. G.Cacciatore, Cultura IJPhC\&A, 2, (2011)

2. M.N.Kokarevich, N.Z Sizova, Procedia Soc. \&Beh.Sc., V., 166, (2015)

3. S. Park, Cultura IJPhC\&A, 1, (2011)

4. A. López-Varela, Cultura IJPhC\&A, 2, (2012)

5. S. Huntington, The Clash of Civilizations and the Remaking of World Order (Simon \& Schuster, 1996)

6. F. Northrop The Meeting of East and West (Macmillan Comp., Ox Bow Press, 1979)

7. O. Paz, The Labyrinth of Solitude (Grove Press, 1985) 